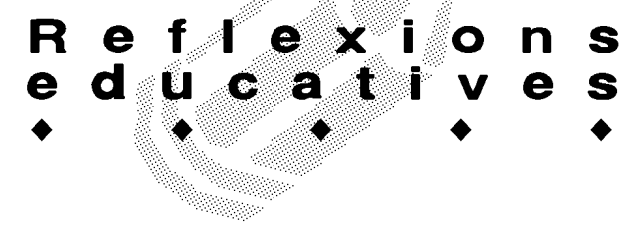

\title{
DIDÀCTICA DE LA BATALLA DE L'EBRE
}

\author{
Francesc Xavier Hernàndez Cardona. Àrea de Didàctica de les Ciències Socials. Universitat de Barcelona
}

\section{La guerra i l'ensenyament}

Els estudiants d'ensenyament primari i secundari han de saber història, i han de saber com s'investiga en història. La història es una disciplina científica que intenta establir què és el que va passar en un moment i un lloc determinat. Els objectes d'estudi de la història són, doncs, molt amplis, i van des de la vida quotidiana fins a fenòmens de gran complexitat, com ara la guerra.

Durant decennis l'ensenyament de la història s'havia vertebrat a partir de fets de militars i polítics. Tanmateix, ni tan sols hi havia una perspectiva científica d'aproximació. El tractament de la guerra es feia des del punt de vista dels valors, i el que es perseguia era estimular valors com ara el patriotisme d'estat nació o el militarisme. Avui dia, afortunadament, comencem a estar lluny d'aquestes funestes tendències que havien impregnat l'ensenyament. Avui l'ensenyament de la història, en el marc de les ciències socials, a l'ensenyament primari i secundari es caracteritza per la diversificació dels objectes d'estudi, varietat que està, a més a més, potenciada pels dissenys curriculars de primària i secundària. Per descomptat, també es planteja l'ensenyament i l'aprenentatge de la història en una perspectiva científica.

En aquesta diversificació dels objectes d'estudi de la història a l'ensenyament primari i secundari entra també la guerra i els fets bèl-lics, fenòmens que han afectat i condicionat els humans, la seva distribució territorial, la seva economia, etc. Estudiar avui la guerra des d'una perspectiva científica no té res a veure amb l'ús que se'n feia fa poques dècades des del punt de vista dels valors. Cal recordar que des d'aquesta perspectiva els valors de la guerra se situaven en una dicotomia bons / dolents, i es obvi que era una història de bons (el mateix estat nació) contra dolents (els altres estats). Ara això ja comença a estar superat. En l'actualitat i en una perspectiva científica ens centrem principalment en la dicotomia vertader/fals, respecte dels fets, independentment que aquests fets es puguin valorar posteriorment, més enllà de la disciplina, des d'una perspectiva cívica o de valors. La història es preocupa, doncs, i fonamentalment d'aproximar al màxim possible, amb el màxim rigor i objectivitat, allò que va passar i el que no va passar (vertader/fals). Fóra un error plantejar la història a partir dels valors, o el que es el mateix, suposaria pocs canvis respecte d'un plantejament acientífic de la història que ha perdurat durant molts anys.

\section{La guerra civil espanyola a les aules}

La guerra civil espanyola és un objecte d'estudi històric com qualsevol altre. Tanmateix, té un valor afegit, i és que el seu coneixement pot ajudar a entendre els precedents que incideixen de manera molt directa en la nostra societat actual. A principis del 1936 Catalunya gaudia d'una certa pau social. Era un petit país que havia guanyat la seva autonomia i que s'obria al món. El govern de la Generalitat va impulsar la cultura, la sanitat, l'ensenyament i la pau social, i va transformar el país en pocs anys. Experiències singulars com el Pla Macià de Barcelona, impulsat per Le Corbusier, o les obres del GATCPAC esdevingueren referents de progrés inqüestionable. Paral-lelament la República espanyola portava endavant iniciatives bàsiques per tal de modernitzar el país: reformes en un exèrcit farcit de generals, la separació entre l'Església i l'Estat, el divorci, el dret de sufragi de les dones, la reforma agrària, etc. Desgraciadament, aquestes tímides mesures van semblar excessives a les classes poderoses, que van promoure un cop d'estat militar contra la democràcia, que aviat va comptar amb el suport internacional de Hitler i Mussolini. El cop militar, al seu torn, va portar la revolució i una llarga guerra de tres anys en la qual es van enfrontar dos models de societat: la republicana democràtica contra la societat de la barbàrie: el feixisme de Hitler, Mussolini i Franco. L'Espanya republicana i Catalunya van perdre la guerra, i les conseqüències van ser desastroses, terribles. Catalunya, concretament, va veure brutalment deteriorada la seva identitat en tots els sentits, cultural inclòs. Catalunya es va convertir en un país vençut i com a tal va ser tractada. Això no són exageracions ni visions tendencioses ni de revenja, és simplement el que va passar. Els poderosos i els militars es van sublevar contra la democràcia i ells van ser els responsables d'una tragèdia terrible. Quina seria la nostra realitat si la República hagués perviscut, amb o sense guerra? Sens dubte la nostra societat tindria ja unes profundes arrels democràtiques, seria una societat més travada, més equilibrada, més justa, més culta i probablement més rica, tot plegat un país capdavanter quant a progrés i llibertat de les persones. És obvi, doncs, que 


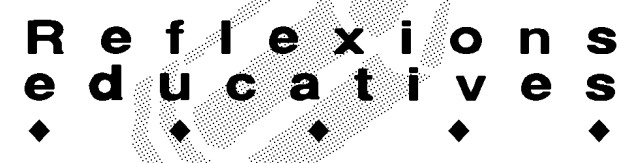

la guerra civil va ser important; res de la nostra realitat actual seria igual sense aquest conflicte. La guerra civil explica els precedents que condicionen el nostre present, amb els subsistemes polític, econòmic, cultural, etc. En aquest sentit, podríem concloure que l'estudi de la guerra civil és important per comprendre i actuar en el present. La guerra civil, doncs, és un tema que també es pot i s'ha de treballar a les escoles de primària i secundària. Tanmateix, fins ara no sembla que sigui important, atès que es tracta poc a les aules. Cal recordar, d'altra banda, que la peculiar transició espanyola a la democràcia formal va suposar un pacte de silenci sobre determinats temes que poguessin ser punyents per a la nova convivència. Però aquesta convivència no es pot construir sobre l'oblit i sobre l'ocultació dels fets. Allò llastimós és que avui dia la llei del silenci s'amagui sota visions expiatòries que invoquin la pau per perpetuar i potenciar un oblit vergonyós: tots vam o van ser culpables, la guerra va ser el producte de la manca de diàleg i de la intransigència, el millor és oblidar, el fonamental és la pau... certament la guerra va ser culpa dels intransigents: aquells que van destruir la democràcia.

\section{Importància de la batalla de l'Ebre}

Si la guerra civil espanyola és encara, seixanta-dos anys després, clau per ajudar a interpretar el present, particularment important ho és la batalla de l'Ebre. Els exèrcits republicans que van combatre a l'Ebre van estar formats, en bona mesura, per joveníssims combatents catalans procedents de les darreres lleves, i homes madurs dels contingents de més edat. L'exèrcit republicà, amb moral de victòria, va travessar el riu buscant una sortida victoriosa a la guerra tot pressionant l'exèrcit de Franco, que s'apressava a conquerir València. S'esperava poder enllaçar amb una propera confrontació europea, atès que feia poc que Alemanya s'havia emparat d'Àustria i amenaçava amb l'ocupació de Txecoslovàquia, aliada de França i de I'URSS. Tot plegat semblava que la confrontació europea era imminent, i que les democràcies donarien suport finalment a la República en contra de Hitler i Mussolini.

La batalla va començar el 25 de juliol del 1938, i es va allargar més de cent dies. Tanmateix, el 30 de setembre la batalla es va perdre a Munic, quan França i el Regne Unit van claudicar davant Hitler i van deixar que aquest annexés Txecoslovàquia a Alemanya. Txecoslovàquia i indirectament la República espanyola van quedar condemnades.

Malgrat tot, els combatents republicans van allargar la resistència de manera inversemblant, esperant que la conjuntura internacional girés al seu favor. Al capdavall

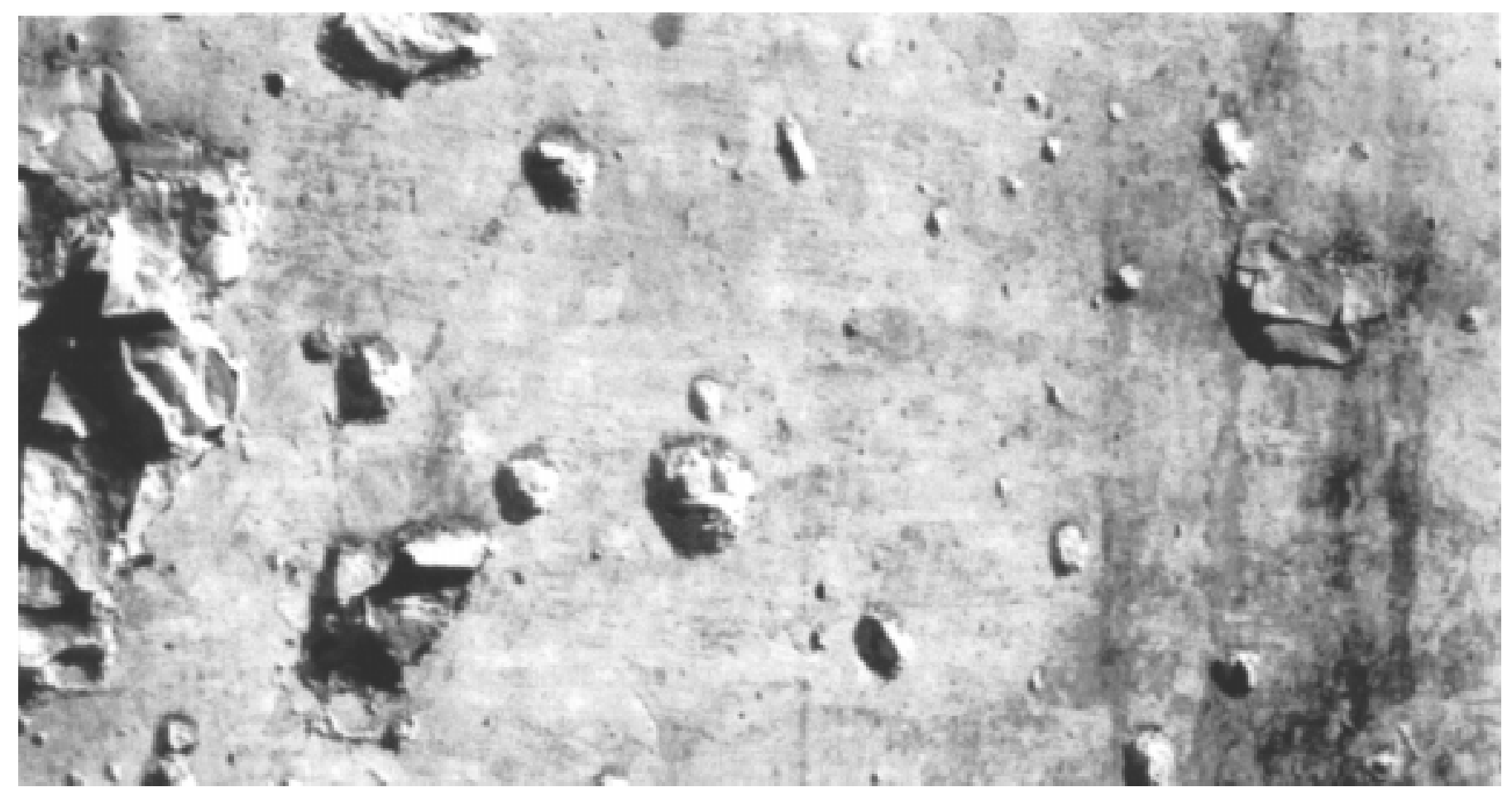

Murs del cementiri de Villalba dels Arcs. Detall dels impactes de projectils en una de les tàpies del cementiri 


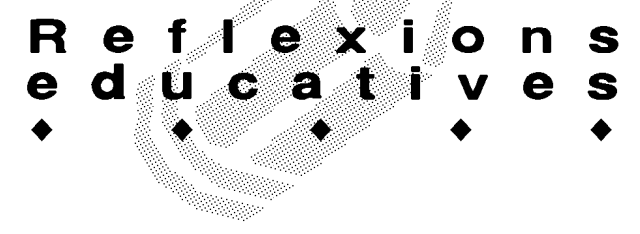

eren joves que majoritàriament defensaven la llar a la cantonada de casa i hom intuïa el desastre que per a Catalunya i la República suposaria la pèrdua de la batalla. Finalment els republicans van ser derrotats per un exèrcit superior i ben armat, que comptava amb el suport militar de Hitler i Mussolini. Després de l'Ebre Catalunya es va ensorrar i va ser ocupada pels exèrcits de Franco. Centenars de milers de persones van haver de fugir a l'exili i altres van patir una repressió salvatge. Els intents de destrucció de Catalunya es van perllongar durant decennis a nivell econòmic, polític, social i cultural. En aquest sentit la batalla de l'Ebre es pot considerar com l'autèntic "onze de setembre" contemporani que estronca i ofega el futur de Catalunya. No cal dir que la batalla de l'Ebre també va ser important per a l'Epanya republicana, per a Europa i per al món. Després de l'Ebre Hitler i Mussolini es van envalentir i van poder prosseguir el seu programa d'agressió: el resultat van ser els cinquanta milions de morts de la Il guerra mundial. Si les democràcies haguessin parat els peus al feixisme a l'Ebre potser s'hauria pogut evitar la II guerra mundial.

Tot plegat l'Ebre és un moment determinant de la història de la Catalunya contemporània, i és per això que l'Ebre s'ha de conèixer. D'altra banda, com hem assenyalat, l'Ebre va impactar brutalment Catalunya, atès que va produir milers de víctimes: soldats morts i ferits, però també fills orfes, germans i pares desconsolats, etc. Encara avui els ecos de la ferida de l'Ebre es deixen sentir entre els catalans.

\section{Una didàctica de la batalla de l'Ebre}

L'estudi d'aquests fets és important per a Catalunya. La cultura de la pau no es pot construir sobre l'oblit o sobre la renúncia. S'ha d'explicar què va passar a l'Ebre i per què va ser important. Tanmateix, tenim avui pocs recursos didàctics per fer comprendre i aproximar la batalla. Comptem, però, amb alguns llibres de memòries i divulgació que, prèvia selecció dels paràgrafs adients $\mathrm{i}$ de la iconografia i cartografia precises, poden ser útils perquè mestres o professors documentin el tema. Volem, però, insistir en la importància de visitar directament els espais del camp de batalla.

Algunes de les zones on es van lliurar els combats més aferrissats de la batalla de l'Ebre han conservat la seva identitat i mostren poques variacions de paisatge respecte a les que van percebre els combatents. La vivència directa de l'espai, combinada amb la informació precisa, pot esdevenir un factor de comprensió i sensibilització important. Sembla com si els avui silenciosos espais de la batalla haguessin conservat els malsons que allí es van viure. Aquestes vivències es poden fer tot i que els espais de la batalla no estan museïtzats ni compten amb indicadors ni plafons informatius ni cap mena d'element d'interpretació. La batalla de l'Ebre es també un fet cultural i s'ha d'abordar, des d'una perspectiva civil, com un fet cultural ampli que es concreta en un territori. El millor per accedir vivencialment a la batalla de l'Ebre es conèixer els seus territoris.

Les visites escolars, tant dels alumnes de primària com de secundària, poden tenir diverses possibilitats i alternatives. Per tal de seguir un ordre cronològic recomanem iniciar l'aproximació a la batalla per la riba esquerra del riu, seguint l'ordre lògic de l'ofensiva republicana.

\section{El castellet de Banyoles}

La visita d'un dia pot començar al castellet de Banyoles, a Tivissa. Aquest punt esdevingué un observatori republicà $i$ és un dels millors miradors sobre el camp de batalla. Usualment es poden distingir les serres de Pàndols, de Cavalls, de la Vall, la Picosa, etc. S'aprecia perfectament el riu i la zona compresa entre Miravet i Móra, un dels sectors per on van travessar els republicans. Justament sota el Castellet, al costat d'on hi ha avui un viaducte de gas travessant el riu, els republicans van col-locar una de les passeres que permetien el pas de la infanteria. El mirador és un bon punt per explicar la preparació de l'ofensiva, el pas del riu i els límits de penetració de l'exèrcit republicà. S'hi pot accedir en autocar fins a la vora del mirador.

La sortida d'un dia pot concloure amb dues possibles alternatives: la Serra de Pàndols o el poble vell de Corbera d'Ebre.

\section{Cota 705 de la serra de Pàndols}

La feréstega serra de Pàndols va ser testimoni d'alguns dels més aferrissats i cruels combats de la batalla. Amb una calor insuportable, sense aigua i amb pocs aliments, els soldats republicans van protagonitzar una duríssima resistència contra l'exèrcit franquista. La cota 705 és el punt més alt de la serra; s'hi pot accedir, amb dificultats, amb autocar. Dalt hi ha un monument dedicat als combatents.

\section{Poble vell de Corbera}

Corbera d'Ebre va patir els estralls dels combats, les ofensives franquistes van destruir el poble. Mai no es va reconstruir. Avui les seves runes són un testimoni fantasmal de la brutalitat d'aquella batalla. La visita pot resultar molt evocadora i s'hi pot accedir amb autocar sense cap dificultat. Avui una escultura, o poema visual, de Brossa recorda els combatents de la llibertat que van participar en la batalla. 


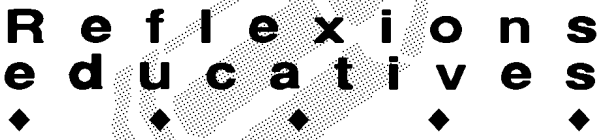

\section{Altres opcions}

Aquesta és una proposta raonable per desenvolupar en un dia. Tanmateix, poden haver-hi altres múltiples alternatives de complement. A Gandesa una associació d'estudiosos de la batalla de l'Ebre ha organitzat una exposició amb armes i restes materials de l'època. Però la visita és de dubtosa utilitat didàctica atès que presenta un discurs implícitament i explícitament militar, mostrant solament armes i uniformes, sense contextualitzar la batalla en el seu ampli entorn cultural. Per dir-ho d'altra manera, presenta una visió de la batalla exclusivament militarista, tot i estar dins de l'anomenada Ruta de la Pau, una proposta per accedir als llocs dels combats que no compta d'altra banda amb elements museogràfics que ajudin a interpretar els objectes d'estudi.

Un cas molt diferent és l'observatori de la Mola de Sant Pau, al poble de la Figuera. Es tracta d'un impressionant observatori fortificat amb molt bona visió sobre les serres de la Fatarella, la Vall, Pàndols i Cavalls. S'hi pot accedir fàcilment amb autocar fins a les rodalies de l'observatori. L'inconvenient és que aquest indret queda molt lluny de tots els altres i es fa dificil (pel llarg trajecte) compatibilitzar aquesta visita amb alguna altra.
Finalment cal destacar una altra possibilitat interessant per a la sortida d'un dia, que és precisament passar l'Ebre pel pas de la barca de Miravet. Es tracta d'una comporta muntada sobre dos llaguts que traspassa el riu aprofitant la força del corrent. En aquest sentit és una experiència important, i d'alguna manera permet reviure el fet i l'emoció de passar el riu. L'inconvenient és que els autocars no caben a la comporta. L'autocar hauria de deixar els alumnes a la rodalia del pas de la barca a Ginestar, i mentre realitzen alguna activitat hauria de fer el tomb i arribar a Miravet per Móra.

En qualsevol cas, tot i que els espais històrics de la batalla de l'Ebre no estiguin museïzats, que no hi hagi elements didàctics d'intermediació, que encara no hi hagi materials per als alumnes $\mathrm{i}$ que els indicadors siguin escassos, cal que els centres de primària i secundària comencin a interessar-se per la descoberta d'aquests espais, testimonis d'un fet tan transcendental en la història de Catalunya. Aquesta presència de joves ciutadans pot contribuir decisivament a la preservació per a les futures generacions dels espais històrics de la batalla de l'Ebre.

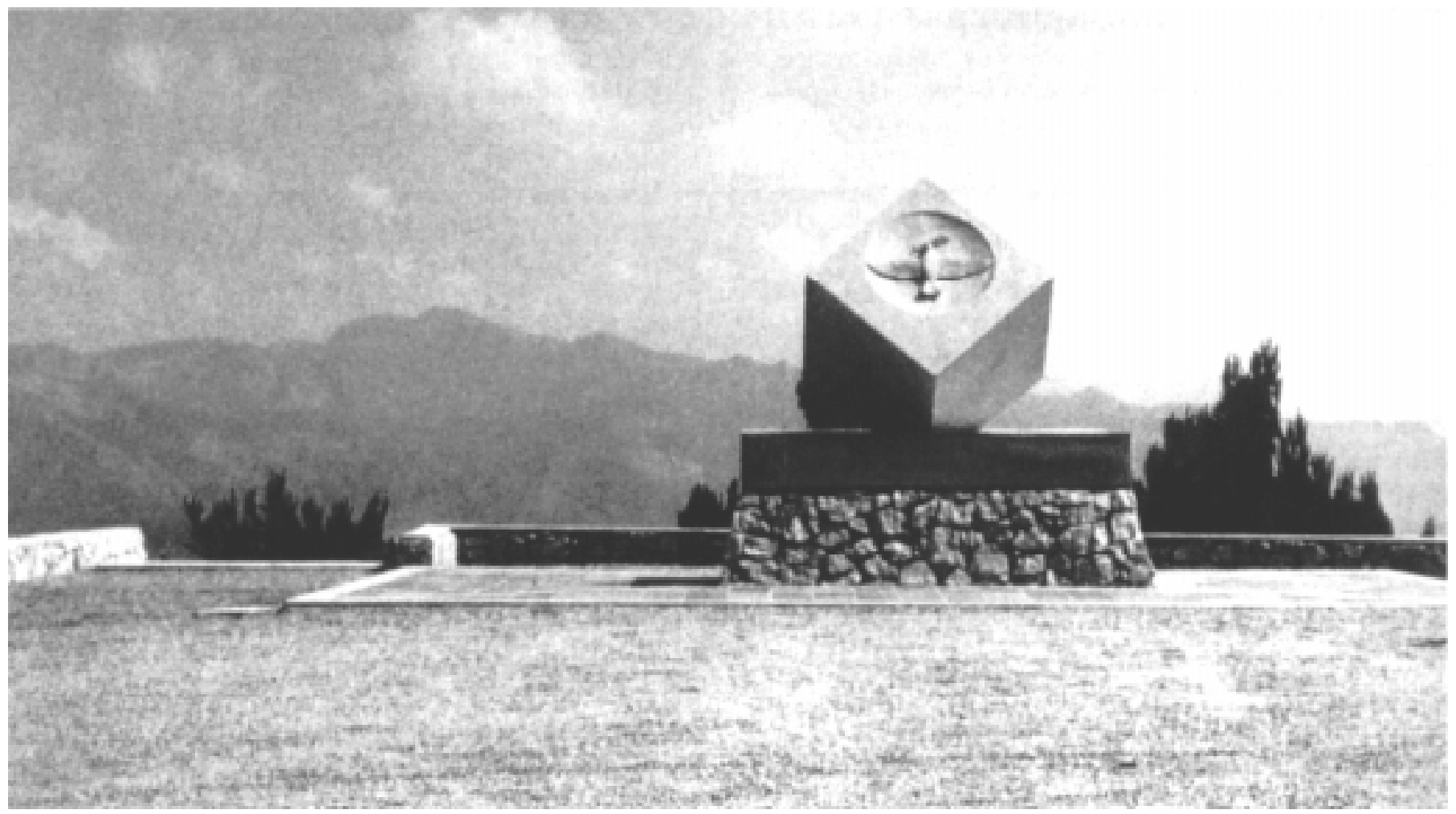

Cota 705 - serra de Pàndols. En aquest punt l'Agrupació "Lleva del Biberó", integrada per excombatents de tots dos exèrcits, van eregir un monument conegut popularment amb el nom "el dado", dedicat a la pau i la reconciliació amb un caràcter expiatori 